\title{
Renal Agenesis: Difficulties and Pitfalls of Antenatal Diagnosis in 5 Cases and Review of the Literature
}

\author{
Imane Attar ${ }^{1 *}$, Hekmat Chaara ${ }^{1}$, Sofia Jayi ${ }^{1}$, Fatima-Zahra Fdili Alaoui ${ }^{1}$, Moulay Abdelilah Melhouf ${ }^{1}$ \\ ${ }^{1}$ Department of Gynecology and Obstetrics II, Chu Hassan II Fes, Morocco
}

DOI: $10.36348 /$ sijog.2021.v04i04.006

| Received: 07.03.2021 | Accepted: 06.04.2021 | Published: 15.04.2021

*Corresponding author: Imane Attar

\section{Abstract}

Renal agenesis is the absence of any trace of kidney, ureter, and therefore the absence of fetal renal function. It constitutes a major field of antenatal screening which presents until now certain limits during ultrasound diagnosis which remains the only accessible, inexpensive and reproducible means of exploration for making the diagnosis with a sensitivity of $85 \%$. The neonatal prognosis is considered better in the unilateral Renal agenesis with functional contralateral kidney, but is always fatal in its bilateral form. The objective of our study is to clarify the ultrasound strategy that must be adopted in antenatal to make the diagnosis while highlighting the technical difficulties that can misdiagnose. An update on the epidemiological and etiopathogenetic nature of the anomaly will also be discussed.

Keywords: Renal agenesis; antenatal diagnosis; Topography; prognosis.

Copyright (C) 2021 The Author(s): This is an open-access article distributed under the terms of the Creative Commons Attribution 4.0 International License (CC BY-NC 4.0) which permits unrestricted use, distribution, and reproduction in any medium for non-commercial use provided the original author and source are credited.

\section{INTRODUCTION}

Renal agenesis is one of the most common congenital anomalies of the urinary tract, its incidence varies from 1 in 500 to 1 in 3200 births [1, 2], but with the advent of routine prenatal ultrasound screening and thanks to improved imaging, this disorder is being diagnosed with increasing frequency.

This condition is defined as the absence of any trace of kidney at the birth of the child which can be unilateral or bilateral, it results from the failure to induce metanephric blastema by the ureteric bud [3].

Due to the difficulties and delay in diagnosis in the past, there has been little data in the literature, and most of the current knowledge comes from observational studies, case reports or case series while analytics studies are absent; therefore, the risk factors and the associated socio-economic conditions that could be responsible for this condition remain unclear [4].

Prenatal ultrasound is the primary imaging tool in detecting lethal and severe renal malformations. Grandjean et al., reported that the sensitivity of a fetal ultrasound between 18 and 22 weeks of amenorrhea to diagnose renal agenesis was $83.7 \%$ in a series of 18 cases whose diagnosis was confirmed on postnatal. The non visualized kidney, bladder and renal artery Doppler coupled with amniotic fluid abnormality after 16 weeks of gestation are strong indicators of renal agenesis. However, this examination has certain limitations which may mislead the prenatal diagnosis [5-8].

The aim of this work will be to examine the accuracy and limitations of ultrasound in the prenatal diagnosis of renal agenesis. As we will report the neonatal prognostic factors.

\section{MATERIALS AND METHODS}

A cross-sectional observational study was designed to examine 180 records of all women who underwent ultrasound in whom a fetal abnormality was detected. We collected 5 cases of renal agenesis (Four bilateral cases and one single unilateral case) out of 36 abnormalities of the urinary tract suspected during antenatal ultrasounds, carried out at the Gynaecology and obstetrics department II of the CHU Hassan II in Fes, France. spanning a period of six years and three months, from January 1, 2011, to March 31, 2017. Data were collected in ascending chronological order from departmental registers, clinical records, and ultrasound reports. All the data were entered using Microsoft 
Imane Attar et al; Sch Int J Obstet Gynec, Apr. 2021; 4(4): 108-113

Office Excel version 2013 software. The results were analyzed using EPI-INFO 7 software.

The clinical and paraclinical parameters studied are:

- Epidemiological criteria: maternal age and consanguinity, personal or family ATCD of genetic disease or urinary tract disease, fetal sex.

- Details of antenatal diagnosis: Age of diagnosis, biometry and amniotic fluid, Morphology of the urogenital system, associated extra-renal malformations.

- Pregnancy outcome and delivery term.

- Postnatal explorations.

\section{RESULTS}

\section{Epidemiology}

During the study period, 5 cases of renal agenesis were detected with an incidence of $13 \%$ for all urinary tract abnormalities, of which $80 \%$ were bilateral while in $20 \%$ of cases the agenesis was a left unilateral agenesis. The mean maternal age was $27.42 \pm 6.72$ years. The majority of affected fetus were male $(80 \%)$. $25 \%$ of the babies were born out of consanguineous marriage. In our series, only one patient had a family
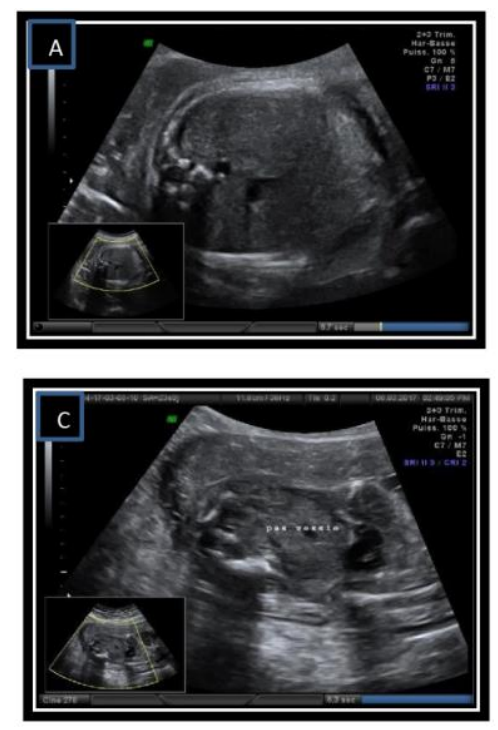

Fig-1: Ultrasound signs suspecting bilateral renal agenesis. (A) absence of visualization of the kidneys (B) absence of renal arteries on color doppler (C) non visualization of the bladder (D) pulmonary hypoplasia secondary to the anamnios
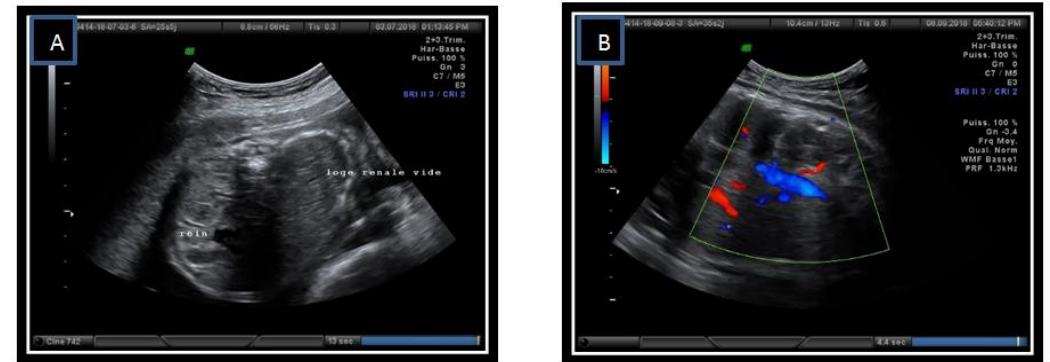

Fig-2: (A) Single left kidney with empty right renal compartment (B) absence of right renal artery on color Doppler 
Imane Attar et al; Sch Int J Obstet Gynec, Apr. 2021; 4(4): 108-113

\section{Pregnancy outcome and delivery term:}

In our series, no therapeutic abortion (TA) was performed. The evolution was towards antepartum fetal death for 2 polymalformative fetus while the three remaining pregnancies were carried to term: one stillborn and two new-borns who died after one day, one of them illustrates the Potter sequence (Fig-3).

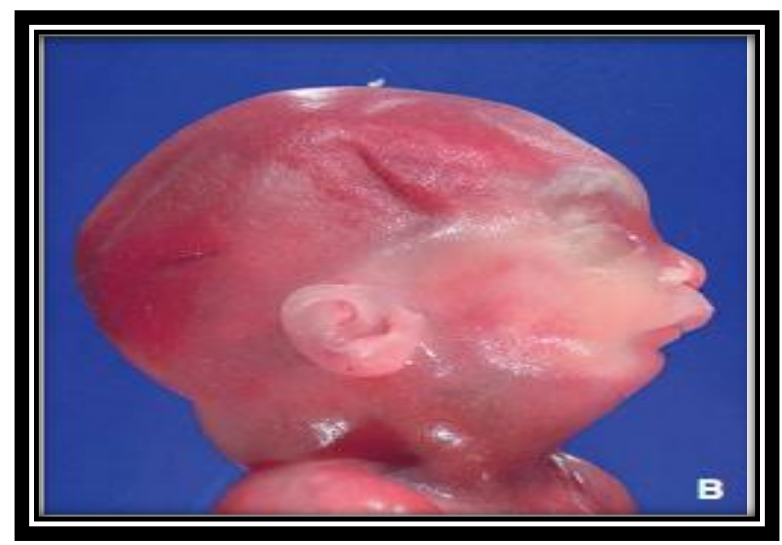

Fig-3: Neonatal appearance of the newborn with Potter facies which is characterized by a flattened nose, an indistinct chin and low set ears

\section{Post-Natal Exploration}

All our new-borns have benefited from a postnatal ultrasound:

- 3 cases of bilateral renal agenesis for which the result of postnatal explorations correlated with antenatal ultrasound.

- 1 case with suspicion of bilateral agenesis, postnatal ultrasound revealed right renal agenesis with an ectopic and dysplastic left kidney.

- For the only unilateral form in our series, ultrasound at birth revealed a small dysplastic left kidney with a large right compensating kidney.

\section{DISCUSSION}

\section{Renal Embryology}

Human renal development is characterized by highly orchestrated interactions between two embryonic structures:

- Metanephric blastema (undifferentiated mesenchyme in the nephrogenic crest): it is the proximal component, which gives rise to glomeruli and tubules up to the distal collecting tubules.

- The ureteral bud: it is the distal component which gives rise to the collecting ducts, the calyces and the pelvis.

During the 5th week of gestation, the ureteral bud comes from the Wolff canal enters the metanephric blastema, then around the 7th week of gestation the genesis of the nephron begins under the influence of the ureteral bud. By the 20th week, the ureteral bud ramifies into 15 generations and forms the entire collecting duct system. At this point, nephrogenesis is only $30 \%$ complete, and further maturation gradually continues until the 36 th week. Then renal agenesis must be the result either of the absence of appearance of the ureteral bud, or of the failure of the engagement of the bud with the renal mesenchyme $[9,10]$.

Renal agenesis should be distinguished from abnormal or incomplete renal development leading to a non-functioning kidney, such as Multicystic dysplastic kidney (MCDK) or renal aplasia [11].

It should be noted that the fetal kidney only plays a minor role in the homeostasis of sodium and water in-utero, but it is the main source of amniotic fluid. Therefore, in renal agenesis, oligoamnios is often an early indicator [12]. In our study there was an increased incidence of oligoamnios.

\section{Epidemiology and etiopathogenesis}

Renal agenesis is one of the most common congenital anomalies of the urinary tract, its incidence varies from 1 in 500 to 1 in 3200 births, this large difference between the different studies is due to differences in the sample size, study design, diagnostic criteria and population selection. The impacts observed in different studies are summarized in the table $[1,2]$.

Men are more frequently affected than women with a ratio of 1.2 to 2.3 [13], matching the results of our series. This has been attributed to the anterior differentiation of Wolff's duct which takes place near the time of ureteric bud formation. The ureteral bud is more likely to be influenced by Wolffian duct abnormalities than by Mullerian duct abnormalities, which develop later in fetal maturation. The left kidney is more often absent during unilateral agenesis as in the case of our fetus [10].

The etiology of renal agenesis is heterogeneous and seems to be multifactorial with environmental and genetic factors such as [10, 14, 15]:

- Several teratogenic molecules reported have been implicated in renal agenesis including retinoids, thalidomide, arsenate and cocaine.

- In mouse, experiments have shown that the genes Wt-1, Pax-2, Emx-2, Lim-1 and many other gene deletions are associated with renal aplasia. In humans, natural mutations of Pax-2, KAL mutation are associated with renal abnormalities.

- Unilateral renal agenesis is frequently associated with caudal regression syndrome, which is observed with increased frequency in diabetic patients.

- Still for the unilateral form, it can be registered in a family history with genetic participation follows an autosomal dominant mode with incomplete penetrance. When a genetic cause is known, a genetic counselor must provide supportive counseling and help. The risk of developing a kidney defect is increased in children, parents and 
Imane Attar et al; Sch Int J Obstet Gynec, Apr. 2021; 4(4): 108-113

siblings of an affected patient (12, 4 and $2 \%$ respectively).

In our series, given the small sample available to us, the study of prenatal factors could not establish a causal link with renal agenesis. No patient in our study was exposed to a particular teratogenic treatment, and no case of pre-existing or gestational diabetes was reported, on the other hand $25 \%$ of our fetus were born out of consanguineous marriage, as well as in only one patient was found to have a family history of down syndrome.

\section{Antenatal Diagnosis}

Prenatal ultrasound is the main inexpensive and accessible imaging modality for the assessment of fetal urogenital tract abnormalities. Currently with the advent of high frequency ultrasound probes the fetal kidneys can be visible from the 1st trimester around the 13 th to 14 th weeks [16]. However, in the event of a diagnosis doubt magnetic resonance imaging (MRI) seems necessary [17].

The kidneys appear as ovoid structures in the lumbar regions on either side of the spine. Their volume gradually increases during pregnancy. Their size is measured and compared to charts of renal growth. Until the 17th-18th weeks, the kidney is relatively hyperechogenic compared to the liver. Its echogenicity then decreases at this moment the cortico-medullary differentiation characteristic of the renal parenchymal architecture appears; the hypoechoic pyramids are triangular well organized around the sinus contrast with the cortex of average echogenicity. The definitive ultrasound appearance is observed around the 26th-27th weeks $[10,13]$.

\section{Bilateral Renal Agenesis}

The absence of fetal kidneys in the renal fossa, an empty bladder and the presence of abnormal amniotic fluid (oligoamnios, anamnios) after 16 weeks of gestation are strong indicators of bilateral renal agenesis [18]. Color Doppler Ultrasound can be used as a diagnostic adjunct. Fetal renal arteries on a posterior coronal section should be viewed as direct branches of the abdominal aorta just below the origin of the superior mesenteric artery. The absence of renal arteries strongly suggests bilateral renal agenesis [19]. For our four cases of bilateral renal agenesis, the ultrasound with Doppler met the criteria for making the diagnosis.

The amniotic fluid abnormality is considered a critical criterion in the diagnosis of bilateral renal agenesis but that from the 16th week of gestation, this is attributed to the fact that the production of fetal urine begins between 8 - and 10-weeks of gestation but it does not contribute significantly to amniotic fluid volume until 16 weeks gestation. Before this gestational age, amniotic fluid is mainly formed by secretions from the placenta, fetal membranes and skin. Although this is of great help for the diagnosis, but once the oligoamnios is present the study of the urinary tract and the search for other associated malformations becomes more difficult $[2,18,19]$.

However, prenatal ultrasound has other limitations that may affect its sensitivity [20, 21]:

- The fact that the fetal kidneys appear echogenic in early pregnancy makes it difficult to differentiate them from adjacent structures.

- The adrenal glands can also be confused with hypoplastic kidney tissue.

Grandjean et al., reported that the sensitivity of a systematic ultrasound examination of the fetus between 18 and 22 weeks gestational age to diagnose bilateral renal agenesis was $83.7 \%$ [5-8], in our series the sensitivity was $75 \%$, a single case diagnosed antenatal as bilateral agenesis whose postnatal exploration showed right renal agenesis with a contralateral ectopic and dysplastic kidney, this had no impact on the prognosis as the ectopic kidney was not functional.

\section{Unilateral Renal Agenesis}

Unilateral renal agenesis is usually detected quietly in infancy when evaluating a urinary tract infection or in adults with hypertension; but with the accuracy of prenatal screening increases, the rate of fetal forms has increased [22].

As a general rule, the ultrasound finding corresponds to an inability to visualize a normal kidney in the renal fossa with an increased size contralateral kidney so-called "compensatory" in $50 \%$ of cases. The antenatal diagnosis can be confronted with difficulties in certain situations [23-26]:

- When the fetal position causes a "shadow" of a kidney.

- If there are no additional abnormal ultrasound findings such as oligoamnios or lack of visualization of the bladder (Except in the event of a contralateral anomaly).

- Or when the adrenal gland enlarges on the side of the agenesis thus mimicking a normal kidney.

Special attention should be paid to the differential diagnosis in case of unilateral agenesis to rule out extreme unilateral renal dysplasia (renal aplasia), multi-cystic renal dysplasia with involution and renal ectopia.

Once the diagnosis is made, the search for malformations of the remaining kidney seems necessary: as the pyelo-ureteral junction (PUJS) found in $11 \%$ of cases, Ureterovesical junction (UVJ) in $7 \%$ of cases and Vesicoureteral reflux (VUR) in $30 \%$ of cases [27-29]. 
Imane Attar et al; Sch Int J Obstet Gynec, Apr. 2021; 4(4): 108-113

\section{Associated Malformations}

Several previous studies have described the malformations that are associated with renal agenesis. Congenital heart defects are the most common up to $44 \%$ (interatrial and interventricular communications), Pulmonary hypoplasia, genital abnormalities (the seminal vesicles Hypoplasia), gastrointestinal abnormalities (anal atresia) and Potter facies. In our series, cardiac malformations and pulmonary hypoplasia were present with a percentage of $40 \%$ but no case of genital or gastrointestinal malformation was detected on ultrasound given the anamnios [10].

Syndromic groupings have also been reported: Turner syndrome, Poland syndrome, Di George syndrome and Kallmann syndrome, VACTRELLE syndrome, etc... [10]; no syndrome was mentioned in our series.

\section{Prognosis}

Bilateral renal agenesis remains a fatal pathology to this day, $40 \%$ of pregnancies are carried to term, but children who are born do not survive beyond 24 to 48 hours. In our series we declared two antepartum fetal death while the others died within 24 hours after childbirth [30].

Regarding the unilateral form, the prognosis seems better in subjects with normal contralateral kidney without other associated extra-renal malformations. However, several cases reported in the literature of repeated urinary tract infection and arterial hypertension which can worsens the prognosis. Our case of unilateral agenesis presented fetal death in utero at 30 weeks as part of a poly-malformation syndrome [30].

\section{CONCLUSION}

This work reinforces the idea that the antenatal diagnosis of renal agenesis is essentially ultrasound with a sensitivity that exceeds $80 \%$, but it is necessary to master the echo-anatomy of the urinary system in order to thwart the ultrasound traps that can disturb the diagnosis. Unfortunately, the antenatal detection of this anomaly in its bilateral form cannot change the prognosis which remains fatal to this day, unlike the unilateral form where the morphological analysis can select cases with a good prognosis which must be directly connected after birth with a Pediatric nephrologists in order to avoid all the complications which can weigh down the functional prognosis.

\section{What is known about this topic}

- The antenatal diagnosis of renal agenesis has become more and more frequent.

- The prognosis of this affection remains fatal for the bilateral form with a better prognosis for the unilateral form.

\section{What's new from your study}

- Our study confirmed the aggressive nature of this entity.

- Ultrasound remains the best diagnostic tool in the hands of an expert, especially in third world countries where access to MRI it's still difficult.

Conflicts of interest: The authors declare no conflict of interest.

Contributions from the authors: All authors contributed equally to this work. All authors also declare that they have read and approved the final version of the manuscript.

\section{REFERENCES}

1. Bienstock, J. L., Birsner, M. L., Coleman, F., \& Hueppchen, N. A. (2014). Successful in utero intervention for bilateral renal agenesis. Obstetrics \& Gynecology, 124(2), 413-415.

2. Isaksen, C. V., Eik- Nes, S. H., Blaas, H. G., \& Torp, S. H. (2000). Fetuses and infants with congenital urinary system anomalies: correlation between prenatal ultrasound and postmortem findings. Ultrasound in Obstetrics and Gynecology, 15(3), 177-185.

3. Song, J. T., Ritchey, M. L., Zerin, J. M., \& Bloom, D. A. (1995). Incidence of vesicoureteral reflux in children with unilateral renal agenesis. The Journal of urology, 153(4), 1249-1251.

4. Parikh, C. R., McCall, D., Engelman, C., \& Schrier, R. W. (2002). Congenital renal agenesis: case-control analysis of birth characteristics. American journal of kidney diseases, 39(4), 689-694.

5. Behairy, N. H. E. D., El Din, L. A. S., Hanoun, N. M. F., Abd El Raof, M., \& Ali, M. A. E. K. (2015). Diagnostic value of fetal MRI in evaluating fetal urinary anomalies. The Egyptian Journal of Radiology and Nuclear Medicine, 46(2), 521-528.

6. Said, A. H., El-Kattan, E., Abdel-Hakeem, A. K., \& Saleem, S. (2016). In utero MRI diagnosis of fetal malformations in oligohydramnios pregnancies. The Egyptian Journal of Radiology and Nuclear Medicine, 47(4), 1733-1742.

7. Plunk, M. R., \& Chapman, T. (2014). The fundamentals of fetal MR imaging: Part 1. Current problems in diagnostic radiology, 43(6), 331-346.

8. Rosenblum, S., Pal, A., \& Reidy, K. (2017, April). Renal development in the fetus and premature infant. In Seminars in Fetal and Neonatal Medicine (Vol. 22, No. 2, pp. 58-66). WB Saunders.

9. Alm, J., Masreliez, V., \& Winbladh, B. (1997). Nelson WE, Behrman RE, Kliegman RM and Arvin AM, editors. Nelson's Textbook of Pediatrics. Acta Pediatrica, 86(1), 56. 
Imane Attar et al; Sch Int J Obstet Gynec, Apr. 2021; 4(4): 108-113

10. Parikh, C. R., McCall, D., Engelman, C., \& Schrier, R. W. (2002). Congenital renal agenesis: case-control analysis of birth characteristics. American journal of kidney diseases, 39(4), 689-694.

11. Hiraoka, M., Tsukahara, H., Ohshima, Y., Kasuga, K., Ishihara, Y., \& Mayumi, M. (2002). Renal aplasia is the predominant cause of congenital solitary kidneys. Kidney international, 61(5), 1840-1844.

12. Vekemans, M., \& Morichon-Delvallez, N. (1995). Uniparental Disomy And Intrauterine Growth Retardation (IUGR). Pediatrics Archives, 2(6), 609.

13. Alm, J., Masreliez, V., \& Winbladh, B. (1997). Nelson WE, Behrman RE, Kliegman RM and Arvin AM, editors. Nelson's Textbook of Pediatrics. Acta Pediatrica, 86(1), 56.

14. Schrier, R. W. (Ed.). (2007). Diseases of the kidney and urinary tract (Vol. 1). Lippincott Williams \& Wilkins.

15. Laski, M. E. (2000). Brenner \& Rector's The Kidney. American Journal of Kidney Diseases, 36(4), 875-876.

16. Economides, D. L., \& Braithwaite, J. M. (1998). First trimester ultrasonographic diagnosis of fetal structural abnormalities in a low risk population. BJOG: An International Journal of Obstetrics \& Gynaecology, 105(1), 53-57.

17. De Cleyn, K., Degryse, H., Slangen, T., De Vree, M. T., Buytaert, P., \& De Schepper, A. (1989). MRI in the Prenatal Diagnosis of Bilateral Renal Agenesis. Röfo - Fortschritte Auf Dem Gebiet Der Röntgenstrahlen Under Bildgebenden Verfahren, 150(1):104-105.

18. Sgro, M., Shah, V., Barozzino, T., Ibach, K., Allen, L., \& Chitayat, D. (2005). False diagnosis of renal agenesis on fetal MRI. Ultrasound in obstetrics \& gynecology, 25(2), 197-200.

19. Dias, T., Sairam, S., \& Kumarasiri, S. (2014). Ultrasound diagnosis of fetal renal abnormalities. Best Practice \& Research Clinical Obstetrics \& Gynaecology, 28(3), 403-415.

20. Alamo, L., Laswad, T., Schnyder, P., Meuli, R., Vial, Y., Osterheld, M. C., \& Gudinchet, F. (2010). Fetal MRI as complement to US in the diagnosis and characterization of anomalies of the genito-urinary tract. European journal of radiology, 76(2), 258-264.

21. Gęca, T., Krzyżanowski, A., Stupak, A., Kwaśniewska, A., Pikuła, T., \& Pietura, R. (2014). Complementary role of magnetic resonance imaging after ultrasound examination in assessing fetal renal agenesis: a case report. Journal of medical case reports, 8(1), 1-4.

22. Jones, P. (2007). Paediatric Surgery and Urology: Long-term Outcomes. MD Stringer, KT Oldham and PDE Mouriquand (eds). 223× $282 \mathrm{~mm}$. Pp. 1071. Illustrated. 2006. Cambridge University Press: Cambridge.

23. Arfeen, S., Rosborough, D., Luger, A. M., \& Nolph, K. D. (1993). Familial unilateral renal agenesis and focal and segmental glomerulosclerosis. American Journal of Kidney Diseases, 21(6), 663-668.

24. Barwick, T. D., Malhotra, A., Webb, J. A. W., Savage, M. O., \& Reznek, R. H. (2005). Embryology of the adrenal glands and its relevance to diagnostic imaging. Clinical radiology, 60(9), 953-959.

25. Roodhooft, A. M., Birnholz, J. C., \& Holmes, L. B. (1984). Familial nature of congenital absence and severe dysgenesis of both kidneys. New England Journal of Medicine, 310(21), 13411345.

26. Yuksel, A., \& Batukan, C. (2004). Sonographic findings of fetuses with an empty renal fossa and normal amniotic fluid volume. Fetal diagnosis and therapy, 19(6), 525-532.

27. Douglas-Denton, R., Moritz, K. M., Bertram, J. F., \& Wintour, E. M. (2002). Compensatory renal growth after unilateral nephrectomy in the ovine fetus. Journal of the American Society of Nephrology, 13(2), 406-410.

28. Maluf, N. S. R. (1997). On the enlargement of the normal congenitally solitary kidney. British journal of urology, 79(6), 836-841.

29. Keller, G., Zimmer, G., Mall, G., Ritz, E., \& Amann, K. (2003). Nephron number in patients with primary hypertension. New England Journal of Medicine, 348(2), 101-108.

30. Argueso, L. R., Ritchey, M. L., Boyle, E. T., Milliner, D. S., Bergstralh, E. J., \& Kramer, S. A. (1992). Prognosis of patients with unilateral renal agenesis. Pediatric Nephrology, 6(5), 412-416. 